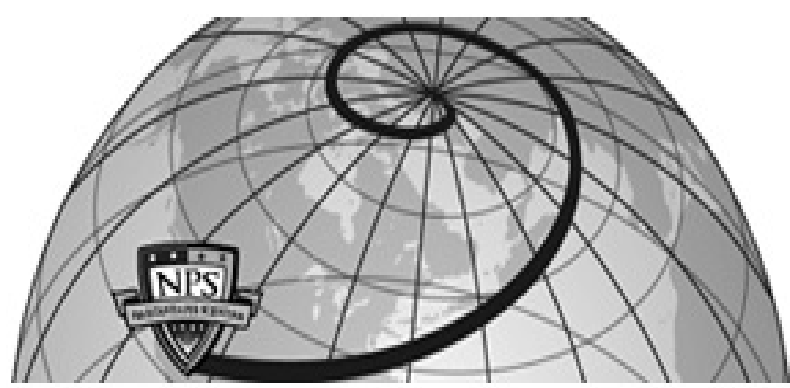

Calhoun: The NPS Institutional Archive DSpace Repository

\title{
Effects of Surface Conditions on Nucleate Pool Boiling of Sodium
}

Marto, P.J.; Rohsenow, W.M.

Journal of Heat Transfer, Transactions of the ASME, May 1966 http://hdl.handle.net/10945/44495

This publication is a work of the U.S. Government as defined in Title 17, United States Code, Section 101. Copyright protection is not available for this work in the United States.

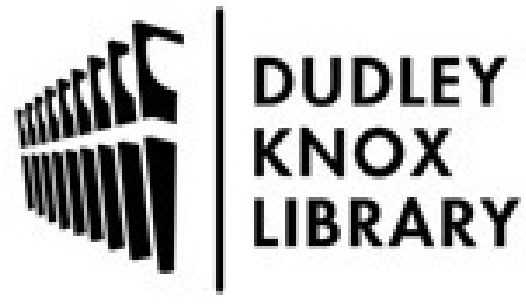

http://www.nps.edu/library
Calhoun is the Naval Postgraduate School's public access digital repository for research materials and institutional publications created by the NPS community. Calhoun is named for Professor of Mathematics Guy K. Calhoun, NPS's first appointed -- and published -- scholarly author.

Dudley Knox Library / Naval Postgraduate School 411 Dyer Road / 1 University Circle Monterey, California USA 93943 


\section{P. J. MARTO \\ Assistant Professor of Mechanical Engineering,
U. S. Naval Post Graduate School, \\ Monterey, Calif. Assoc. Mem. ASME \\ Effects of Surface Conditions on Nucleate Pool Boiling of Sodium}

W. M. ROHSENOW

Professor of Mechanical Engineering, Massachusetts Institute of Technology,

Cambridge, Mass. Mem. ASME
Commercial grade sodium was boiled from a horizontal disk at pressures of $65 \mathrm{~mm}$, $200 \mathrm{~mm}$, and $400 \mathrm{~mm} \mathrm{Hg}$ absolute, with sodium temperatures ranging from $1200 \mathrm{~F}$ to 1500 deg F. Heat fluxes as high as 236,000 Btu/hr sq ft were attained. Boiler surface finishes ranged from highly polished mirror finishes to coarse, porous coatings.

By following a prescribed cleaning and filling procedure, nucleate-boiling results were generally reproducible for a given-type surface. The effect of roughness as well as any aging and hysteresis effects were experimentally determined. Incipient nucleate boiling results are discussed as well as the effect of pressure and pool depth on the mucleateboiling curve.

\section{Introduction}

Recent advances in the technology of fast nuclear reactors, space auxiliary power systems, and of regenerative fuel cells have heightened interest in understanding the boiling of alkali metals.

Lyon, Foust, and Katz [1] ${ }^{1}$ boiled mercury, sodium, sodiumpotassium alloy, and cadmium on a horizontal, stainless-steel cylinder, $3 / 4$-in. OD. Madsen and Bonilla $[2,3]$ boiled potassium and a sodium-potassium alloy on a horizontal, low-carbon nickel disk, 3-in. dia. Noyes $[4,5]$ boiled sodium on horizontal, $3 / 8$-in-OD cylinders, one of molybdenum, the other of stainless steel. Colver [6] boiled potassium on a $3 / 8$-in-OD tube of Haynes 25.

The effect of surface conditions on nucleate boiling of liquid nonmetals has received much attention. Corty and Foust [7] showed the effect of surface roughness on the position and slope of the nucleate-boiling curve ( $q / A$ versus $\Delta T$ ) for R-113, diethyl ether, and n-pentane on copper and nickel surfaces. Berenson [8] studied n-pentane boiling on copper, nickel, and inconel horizontal surfaces of various surface finishes, carrying his tests into the transition-boiling and the film-boiling regions. Bonilla, Grady, and Avery [9] showed that sharp parallel scratches lowered the surface temperature at a given heat flux both for water and for mercury with 0.1 percent sodium. A number of investigators $[10,11,12,13]$ have studied the effects of additives to both the liquid and the heat surface. Young and Hummel [14] showed a significant lowering of surface temperature at a given heat flux when a number of small spots on the heating surface were coated with Teflon.

${ }^{1}$ Numbers in brackets designate References at end of paper.

Contributed by the Heat Transfer Division of The American Society of Mechanical Engineers and presented at the ASME-AIChE Heat Transfer Conference and Exhibit, Los Angeles, Calif., August 8-11, 1965. Manuscript received at ASME Headquarters, May 20, 1965. Paper No. 65-HT-51.
It has been difficult to explain the variation in data of previous alkali metal investigations. We believe that the primary cause of these variations is the effect of surface conditions.

For this reason we attempted to perform a systematic investigation of the effect of surface conditions on nucleate boiling of an alkali metal.

Since the alkali metals appear to wet all metals at temperatures near their boiling points $[15,16]$, and since they are so chemically active with most material, it seems reasonable to assume that surface variables may pliy a larger role in boiling of alkali metals than in boiling of ordinary fluids.

\section{Description of Equipment}

In the experimental apparatus, sodium boiled off a horizontal flat disk, the vapors rose inside a vertical pipe, and condensed as the result of forced convection of air. The apparatus is shown schematically in Fig. 1.

For run numbers 1 through 11 the boiler was a $2^{1 /} /{ }_{2}$-in. schedule 40, stainless-steel 316 pipe, $1 \mathrm{ft}$ long. For runs 17,18 , and 19 the inside surface of this pipe was polished to a mirror finish. The pipe passed through the center of the vacuum-chamber cover and was heliarc welded directly to the bottom of the cover. This pipe was flanged 9 in. above the boiler surface and was heliarc welded in place. The weld, having an approximate penetration of 0.040 in., was ground off each time it was desired to open the boiler section and change the boiler surface. About a dozen welds were obtained with each set of flanges. A single vertical thermocouple probe which was a $1 / 4^{-}$-in-OD $\times 1 / 8$-in-ID stainlesssteel 316 tube could be moved vertically to monitor the temperature distribution within the sodium.

Boiling took place from a horizontal flat disk $2 \% / 16$ in. dia $\times 3 / 4$ in. thick, which was made either of stainless steel 316 or nickel "A," Fig. 2. The disk was heliarc welded to the stainless-steel pipe wall by means of 0.020 -in-thick mating flanges. This method of attachment was decided upon because the weld could be ground off, leaving the boiler plate ready for refinishing and for rewelding. Each set of flanges could be used about four times. The heating surface made a tight fit with the pipe.

$$
\begin{aligned}
& \text { Nomenclature- } \\
& \Delta q=\text { step change in heat flux near a } \\
& T_{\text {sat, } w}=\text { saturation temperature at the } \\
& T_{w}=\text { surface temperature of the boiler } \\
& y=\text { distance into the liquid, meas- } \\
& \text { ured from the boiler surface } \\
& \sigma=\text { surface tension } \\
& \rho_{v}=\text { density of the vapor }
\end{aligned}
$$




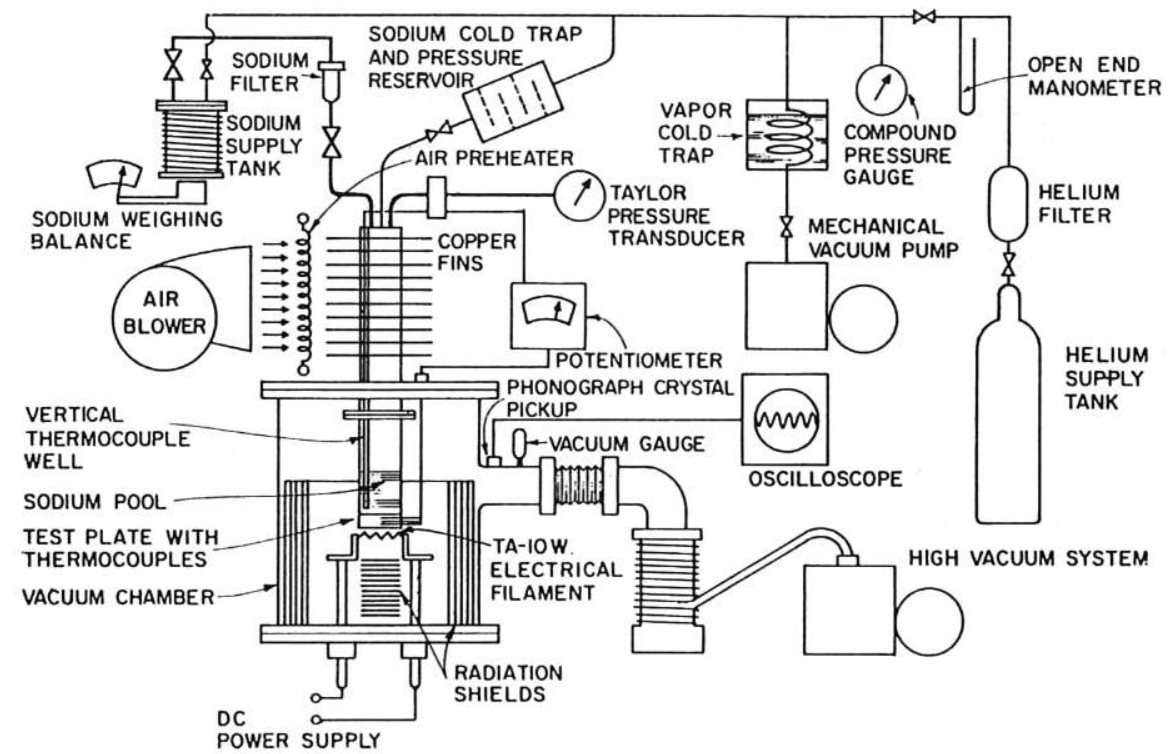

Fig. 1 Schematic diagram of apparafus
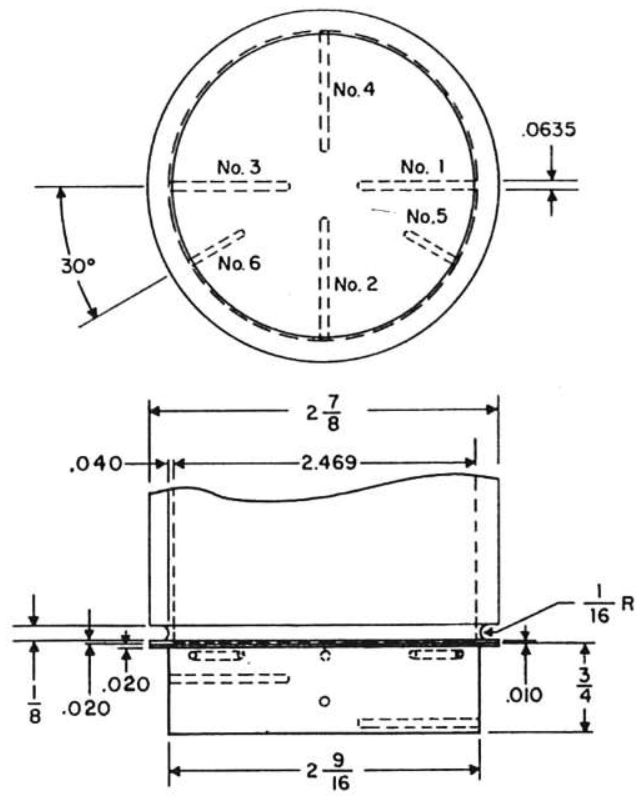

T.C. NO. IMMERSION LENGTH DISTANCE BOILER SURFACE

$\begin{array}{ll}1.0 \mathrm{IN} . & 0.660 \mathrm{IN} . \\ 1.0 \mathrm{NN} & 0.470 \mathrm{IN} . \\ 1.0 \mathrm{NN} . & 0.280 \mathrm{IN} . \\ 1.0 \mathrm{IN} . & 0.090 \mathrm{IN} . \\ 0.5 \mathrm{~N} . & 0.090 \mathrm{IN} . \\ 0.5 \mathrm{IN} . & 0.090 \mathrm{IN} .\end{array}$

Fig. 2 Defails of boiler

Six thermocouple wells, 0.0635 in. dia, were drilled. Four of these penetrated radially to a depth of $1.0 \mathrm{in}$. and had center-line distances from the test surface of 0.090 in., 0.280 in., 0.470 in., and $0.660 \mathrm{in}$. Two other wells, on the 0.090 -in. plane, penetrated to a $1 / 2$-in. depth and were circumferentially orientated $120 \mathrm{deg}$ from each other and from the well with the 1.0-in. depth. The thermocouples were $1 / 1 \sigma^{-i n-O D}$ inconel-sheathed, "Ceramo" platinum-10 percent rhodium couples, calibrated up to $2000 \mathrm{~F}$. Measurements were made on $\mathrm{L}$ and $\mathrm{N}$ type $\mathrm{K}$ potentiometers. These readings were used to obtain the heat flux and were extrapolated to obtain the surface temperature.
For runs 12 through 16 and 20 through 30 , the lower $3^{1 / 2}$ in. of the boiler pipe was replaced by a $2^{1} /{ }^{2}$-in. schedule 40 , nickel " $A$ " pipe welded to the test plate. This piece of pipe was polished internally to a good-quality mirror finish. This was intended to prevent "rogue" nucleation sites, i.e., nucleation sites not on the test surface, from appearing.

The condenser section was a vertical, 28 -in. length of $2^{1 / 2}$-in. schedule 40, stainless-steel 316 pipe with 18 copper fins, 18 in. long $\times 1 \frac{1}{4}$ in. wide $\times 1 / 16$ in. thick, silver soldered on the outside. Cooling air was ducted across these fins.

To interchange boiler surfaces quickly and with relative ease, it was necessary that the main heater should not be an integral part of the boiler test plate; therefore, radiant heating was decided upon. The heater consisted of three tantalum-10 percent tungsten filaments fastened in series between four tantalum clamps. The filaments were 0.010 in. thick $\times 1$ in. wide $\times 4$ in. long. They were fabricated by corrugating a $0.010 \times 3 \times 4$-in. foil along the 4-in. axis with an internal angle of $30 \mathrm{deg}$.

To increase the thermal efficiency of the heater as much as possible, 11 concentric radiation shields were used. In addition, 15 horizontal radiation shields of stainless-steel 304, 0.019 in. thick $\times 3$ in. wide $\times 6$ in. long, were placed bieneath the filaments. All these shields were polished on the i nsde surface to a mirror finish.

The boiler and heater were contained in a vacuum chamber sealed with aluminum or copper $\mathrm{O}$ rings. During operation a vacuum better than $10^{-4} \mathrm{~mm} \mathrm{Hg}$ was held to prevent oxidation embrittlement of the heating elements.

To maintain the sodium as free of oxides as possible, helium was used as a cover gas. The helium was dried and filtered by flowing through a Linde molecular-sieve bed at liquid-nitrogen temperatures. The sodium was filtered before charging the system.

A phonograph crystal cartridge was taped to the high-vacuum line and picked up boiling noise. The electrical signal was fed either to an oscilloscope or a Sanborn recorder.

Pressure was measured by an open-end manometer in the helium line and by a Taylor high-temperature volumetric pressure transducer in the vapor space. These two readings were always-within $2 \mathrm{~mm} \mathrm{Hg}$ of each other. The average of the two readings was used to determine the saturation temperature to an estimated precision of $\pm 4 \operatorname{deg} \mathrm{F}$.

The hydrostatic head resulting from the depth of sodium above the heating surface produces a higher pressure and hence saturation temperature at the actual heating surface, approximately 


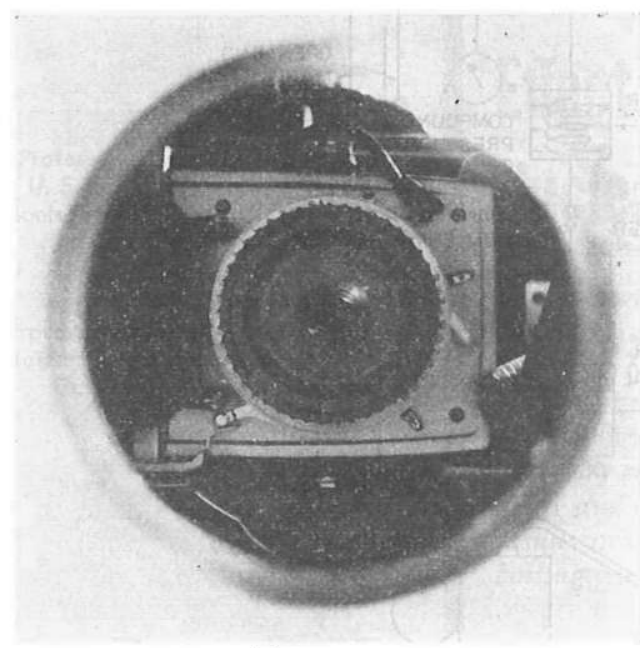

(a) Mirror 1

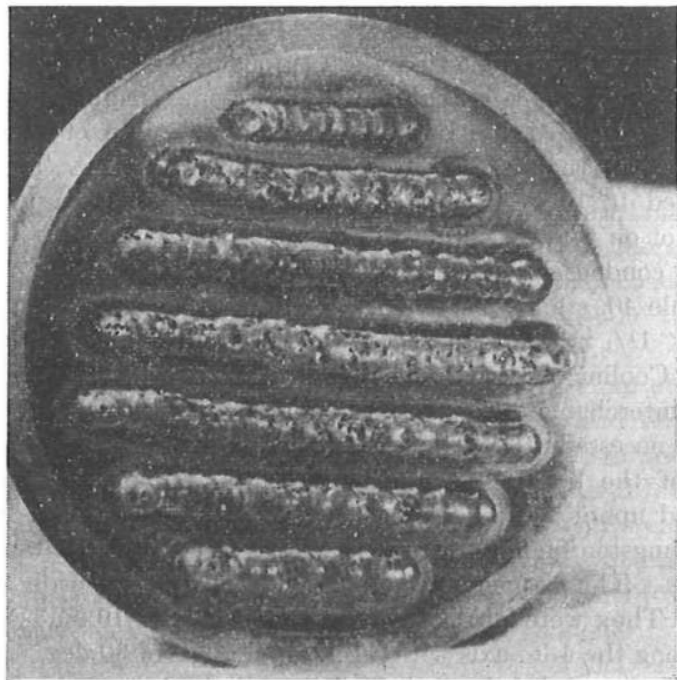

(b) Porous weld

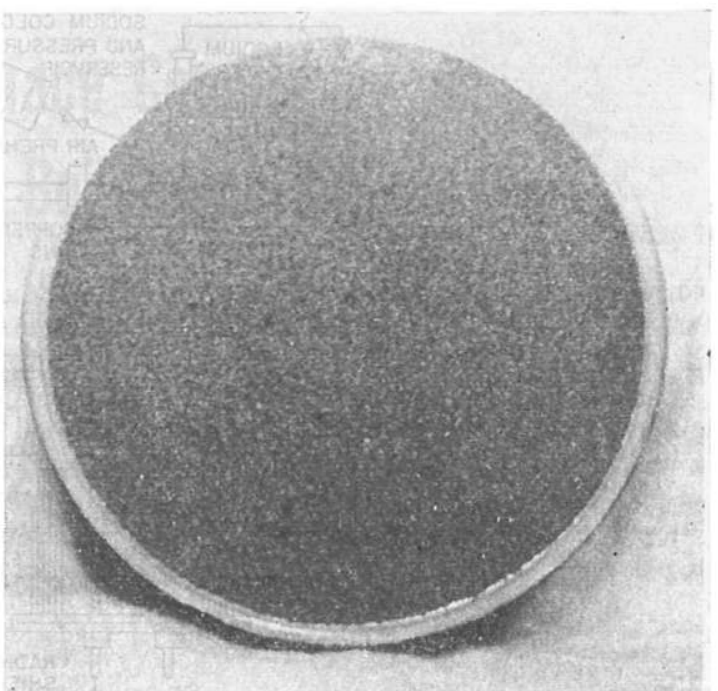

(d) Porous coating

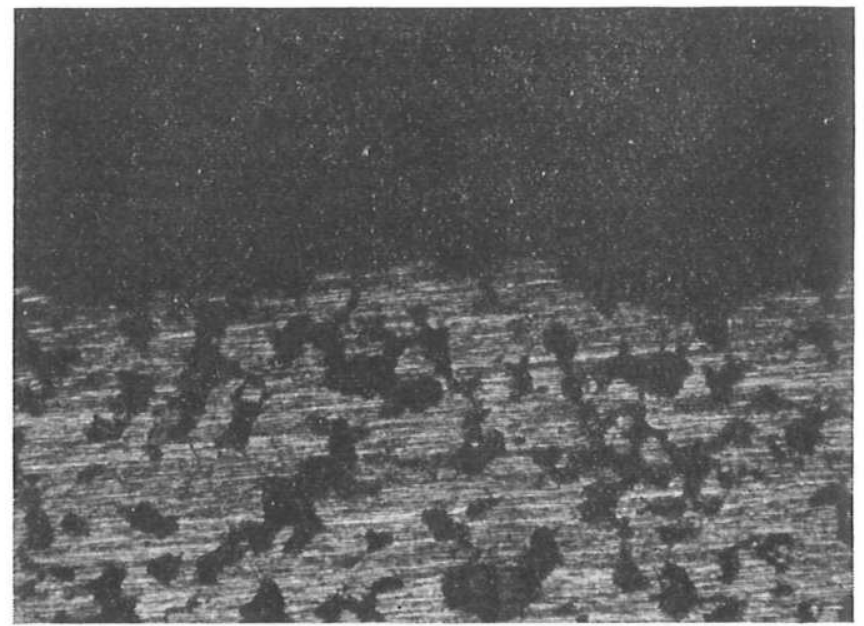

(e) Photomicrograph of $35 \mu$ porous plate $(100 \times)$

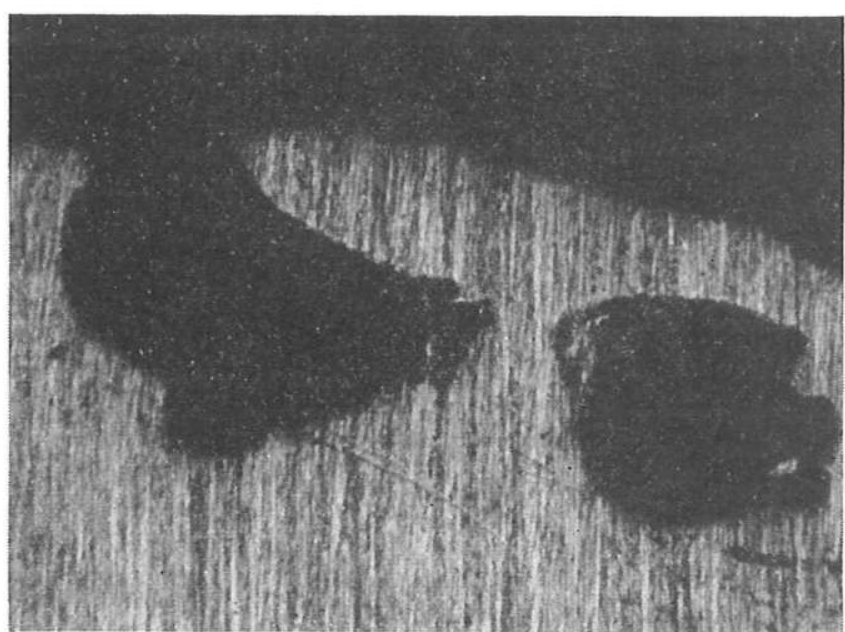

(c) Photomicrograph of porous weld (100X)

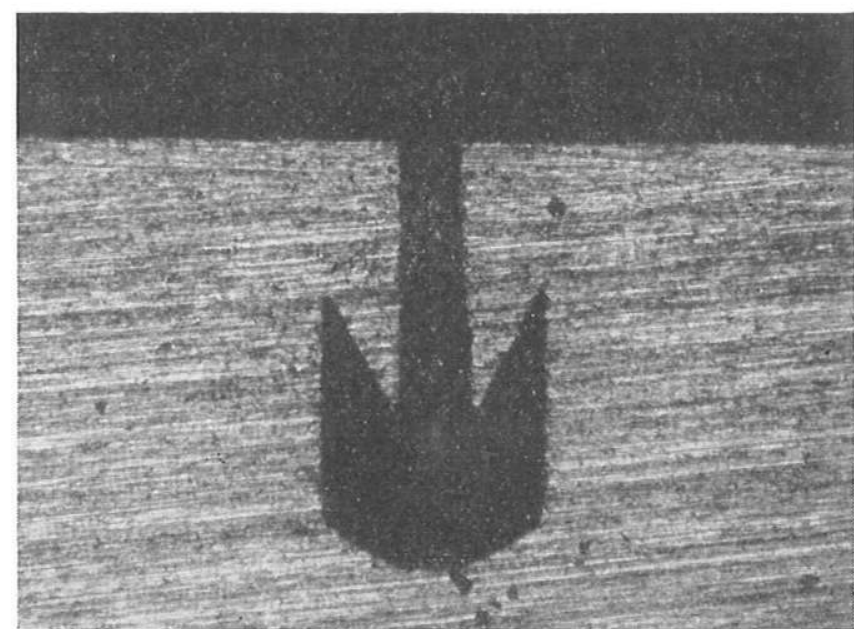

(f) Photomicrograph of doubly reentrant cavity 0.004 -In-mouth dia $X$ 0.025 in. deep $(75 \times)$

Fig. 3 Surfaces tested 


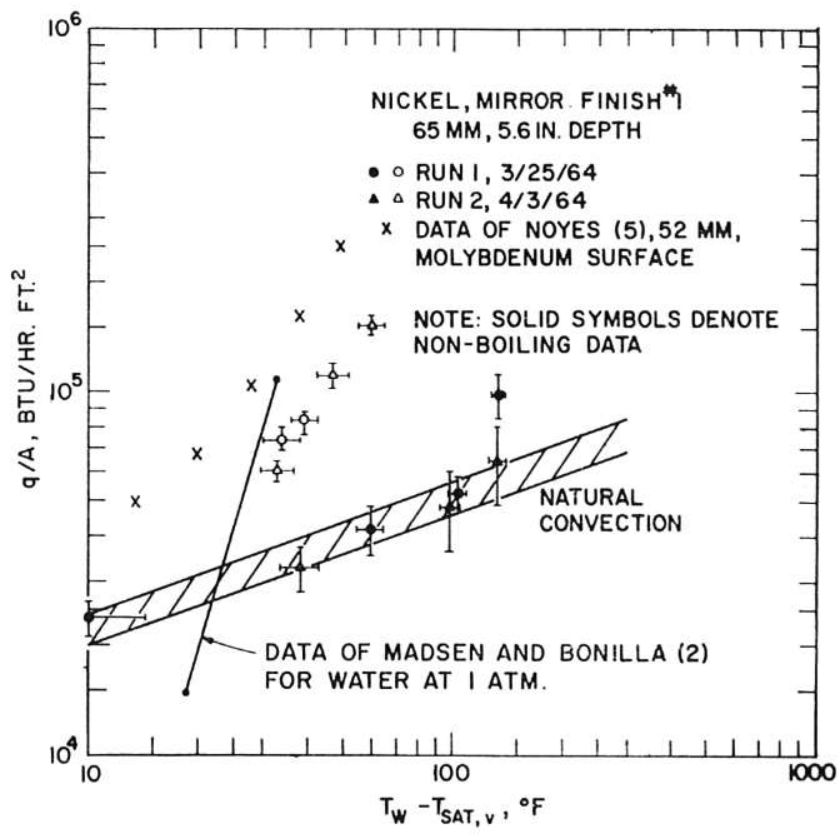

Fig. 4 Sample data with experimental error limits showing sodium data of Noyes and water data of Madsen and Bonilla for comparison

$3 \mathrm{deg} \mathrm{F}$ per in. of depth at a pressure of $60 \mathrm{~mm} \mathrm{Hg}$. (See Appendix for magnitudes). The vertical thermocouple probe was insulated electrically from the container and hence could be used to determine the charge level of sodium by lowering the probe until electrical contact was made with the liquid-metal surface. During operation, however, the hydrostatic head was somewhat less than this because of the liquid condensate in the upper chamber.

Two magnitudes of saturation temperature were calculated: $T_{\mathrm{Bat}, v}$ based on the pressure in the vapor space above the liquid and $T_{\mathrm{sat}, w}$ corrected for the charge hydrostatic head at the heating surface. Most of the data are plotted using $T_{\text {sat. } v}$ because the actual hydrostatic head during operation is not known precisely.

\section{Preparation of Test Surfaces}

Throughout this research work many types of test surfaces were used, ranging from smooth to very coarse. All but one of these test surfaces were welded directly to sections of boiler pipe whose inside surfaces had either standard pipe finishes or mirror finishes. One test section was fabricated by machining a 3 -in-dia solid nickel " $\mathrm{A}$ " rod into the shape of a cup having an overall height of $4^{1} / 2$ in. The details and dimensions of this cup were identical to those given in Fig. 2, but this test section had no joints nor welds beneath the liquid-sodium level.

Mirror Finish. Rough polishing was done on a manual grinder using 240 to 600 -grit emery paper. The test surface was then placed in a Syntron vibratory polishing machine for $20 \mathrm{hr}$ to obtain a fine polish, Fig. 3(a).

Lapped Finish. Lapping generally is thought of as a smoothing or polishing procedure. In our case, however, it was used to roughen test surfaces. The lapping compound contained small pieces of abrasive suspended in oil.

Lapping took place on a rectangular steel plate which had been coated with Clover lapping compound, grade A (280 grit) and grade $\mathrm{F}$ (100 grit).

Artificial Porous Welds. One test section was prepared by taking Mirror 3 and placing seven rows of artificial welds on the surface. These welds were deliberately made porous to create many nucleating sites. They were fabricated by heliarc welding with argon gas using too small a gas cup, too much current, and too long a tungsten electrode. These conditions allowed argon gas pockets to form in the molten metal causing "blowback." Fig. $3(b)$ shows this test surface. Note the large number of exposed cavities. A cross-sectional cut of a sample porous weld disclosed that many of these cavities were reentrant in nature, Fig. 3(c).

Porous Coating. This surface was fabricated by sintering a $1 / 32$-inthick disk of porous nickel " $\mathrm{A}$ " (mean pore size 65 microns) onto the normal nickel " $\mathrm{A}$ " test plate, Figs. $3(d)$ and 3(e).

Artificial Cavities. Twelve doubly reentrant cavities were placed on another mirror surface. They were fabricated by drilling a hole 0.0145 in. dia $\times 0.025$ in. deep in the test surface. A plug, $0.015 \mathrm{in}$. dia $\times 0.015 \mathrm{in}$. long, which was tapered on one end with a 45-deg bevel, was press-fitted into the hole in the test surface so that the top of the plug was flush with the top of the surface. This plug had a 0.004-in-dia hole drilled along its longitudinal axis to provide a mouth for the cavity, Fig. $3(f)$. The 12 cavities were arranged approximately $1 / 2$-in. apart.

Cleaning Procedures. After the equipment was initially assembled, it was thoroughly cleaned of oxides and grease. The entire apparatus was filled with a 50 percent dilute solution of hydrochloric acid for $12 \mathrm{hr}$. The acid then was drained out and the apparatus was flushed several times with distilled water. Trichloroethylene was then added as a degreaser. After soaking for about $12 \mathrm{hr}$, the trichloroethylene was drained out and the distilled-water flushing procedure was repeated. Reagent grade acetone was used as the final rinse.

\section{Results and Discussion}

Fig. 4 presents some typical experimental data with estimated error limits for a nickel "A" surface having a mirror finish. The data of Noyes [5] for sodium on a horizontal molybdenum tube at $52 \mathrm{~mm} \mathrm{Hg}$ and the data of Madsen and Bonilla [2] for water at $1 \mathrm{~atm}$ are plotted for comparison.

Several runs were made with the same surface on two different dates, between which the system was disassembled, cleaned, and reassembled. In every such case the data were reproducible. Shown in Fig. 4 are data for two such runs.

\section{Incipience of Nucleate Boiling}

Fig. 4 also shows that the incipience, or onset, of nucleate boiling does not occur until a superheat $\left(T_{w}-T_{\mathrm{sat}, v}\right)$ of $135 \mathrm{~F}$ is reached even though the stable nucleate boiling data have a superheat of only $33 \mathrm{~F}$. This large overshoot of superheat with increasing heat flux is characteristic of all the sodium data, although the exact superheat value did vary depending on the surface condition.

To understand why this excess superheat exists for sodium, and why it varies with surface condition, we present the analysis of Bergles and Rohsenow [17] which is a modification of Hsu's [18] criterion of incipient boiling. In this analysis [17], nucleation is said to occur when the temperature-gradient line near the wall

$$
\left(\frac{d T}{d y}\right)_{y=0}=-\frac{(q / A)_{0}}{k}
$$

intersects the curve representing the superheat required for a spherical bubble of radius $r$ to grow. With properties $\rho_{v}$ and $h_{f_{0}}$ evaluated at the average temperature, this curve is represented approximately by

$$
T_{v_{i}}=\frac{T_{\mathrm{Bat}}}{1-\frac{2 \sigma}{\rho_{i} h_{f o} r}}
$$

Incipient nucleation is said to occur when the two curves are just tangent provided active cavities of radius $r$ at the point of tangency are available in the heating surface.

A short table of results showing this variation is given in Table 1. 
Table 1 Wall superheat at incipient and stable boiling

\begin{tabular}{|c|c|c|c|c|}
\hline $\begin{array}{l}\text { Surface } \\
\text { Condition } \\
\end{array}$ & $\left(B T U / h r f t^{2}\right)$ & $\begin{array}{l}T_{w}-T_{\text {sat, }} \\
\text { Incipient } \\
\text { Nucleation }\left({ }^{\circ} \mathrm{F}\right)\end{array}$ & $\begin{array}{l}\text { Bubble Radius } \\
\text { at Inciplent } \\
\text { Nucleation(in.) }\end{array}$ & $\begin{array}{c}T_{W}-T_{\text {sat, }} \\
\text { Stable Nucleate } \\
\text { Boiling }\left({ }_{F}\right) \\
\end{array}$ \\
\hline Mirror 1 & 63,700 & 118 & 0.0012 & 16 \\
\hline Lap $F$ & 62,800 & 76 & 0.0018 & 9 \\
\hline Porous Welds & 58,200 & 71 & 0.0019 & 14 \\
\hline $\begin{array}{l}\text { Doubly Re-entrant } \\
\text { Cavities }\end{array}$ & 59,200 & 48 & 0.0028 & 1 \\
\hline
\end{tabular}

In Table $1, T_{\mathrm{sat}, w}$ is computed from the charged depth of liquid. In operation, some of this liquid is in the upper chamber as condensate; hence, the magnitudes of $T_{w}-T_{\mathrm{sat}, w}$ are slightly greater than those listed in the table.

In Fig. 5, equation (2) is plotted both for sodium at $60 \mathrm{~mm}$ $\mathrm{Hg}$ and for water at $1 \mathrm{~atm}$. Also shown are the temperature distributions in the sodium at incipient boiling for the condition listed in Table 1. For comparison, the temperature distribution in water for a heat flux of $60,000 \mathrm{Btu} / \mathrm{hr} \mathrm{sq} \mathrm{ft} \mathrm{is} \mathrm{shown.} \mathrm{Because}$ of the high conductivity of sodium the temperature gradient is very small and the point of tangency, far off the right side of the graph, suggests that very large cavities $(r \simeq 0.1 \mathrm{in}$.) tend to be the first to nucleate at rather low wall superheat of around $5 \mathrm{~F}$. Since no cavities of this size exist, greater superheats are required and overshoot occurs.

The intersection of the two curves, equations (1) and (2), indicates the approximate size of the cavities which first nucleate. These radii are tabulated in Table 1.

The only surface whose cavity size we know with certainty is the one with the doubly reentrant cavity with a drilled radius of 0.002 in. The intersection plotted in Fig. 5 shows good agreement, suggesting a bubble radius of 0.0028 in. Permitting this line of reasoning to extend to the other surface, one concludes that the cavity sizes in the mirror finish are smaller than those in the lap $\mathrm{F}$ and porous-weld surfaces.

It is worthwhile to note that even with the mirror finish, no superheats were observed which were as high as reported by Balzhiser [19] (400 F superheat with potassium) or Hoffman and Krakoviak [20] (700 F superheat with potassium). This may be because of the commercial-grade sodium used in this investigation. Particles of graphite or dirt, contained within the commercial-grade sodium or picked up by it during transfer, may have nucleated within the sodium at the superheats observed during this investigation. These particles would have to be about $0.001-$ in. dia to contain an active site which would nucleate at liquid superheats near $150 \mathrm{~F}$. It is difficult to visualize cavities as large as $0.001 \mathrm{in}$. being present in the mirror finish, Fig. 3(a).

Shown for comparison in Fig. 5 are the nucleation conditions for water. At the same level of heat flux of around 60,000 Btu/$\mathrm{hr} \mathrm{sq} \mathrm{ft}$, there would be a much steeper temperature gradient in the liquid as shown. Also, the curve representing $T_{v_{i}}$, equation (2), for water is displaced to much smaller bubble sizes and temperatures than for sodium.

\section{Wall Superheat During Stable Boiling}

As observed in Figs. 4 and 10-12, initially the wall temperature rises to a high value and drops significantly when nucleate boiling is established. This effect probably is explained by the following mechanism initially postulated by Moore and Mesler [21] and experimentally confirmed by Bonnet, et al. [22]. Measurements of surface temperature under a bubble are represented by the sketch in Fig. 6. It is postulated that the history of bubbles looks somewhat like the series of sketches in Fig. 6. With the vapor inside the bubble essentially at saturation temperature, only a very small temperature drop is required across the microlayer of liquid adjacent to the surface. Therefore, heat is removed much more rapidly from the wall under the

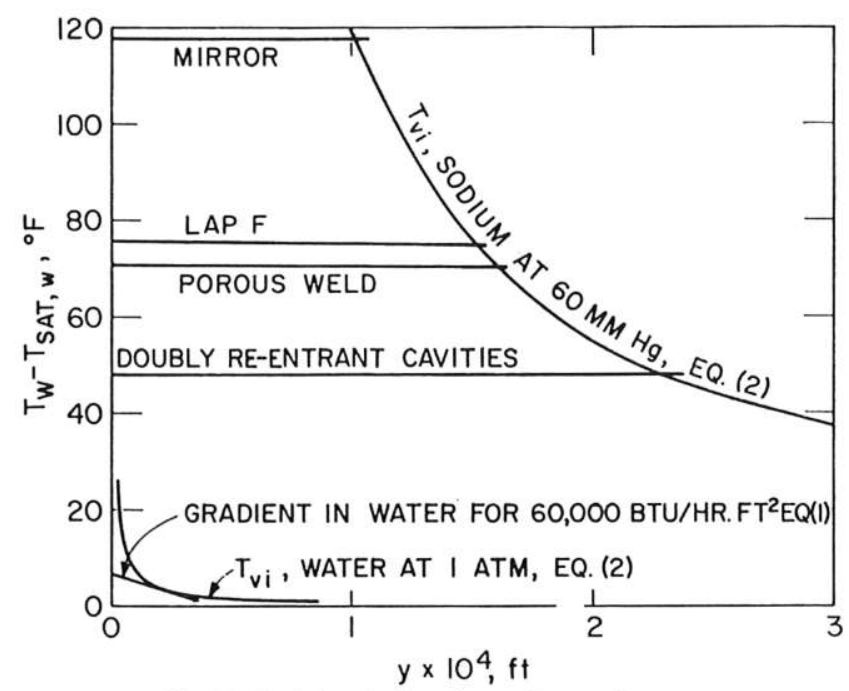

Fig. 5 Incipient boiling for sodium and water
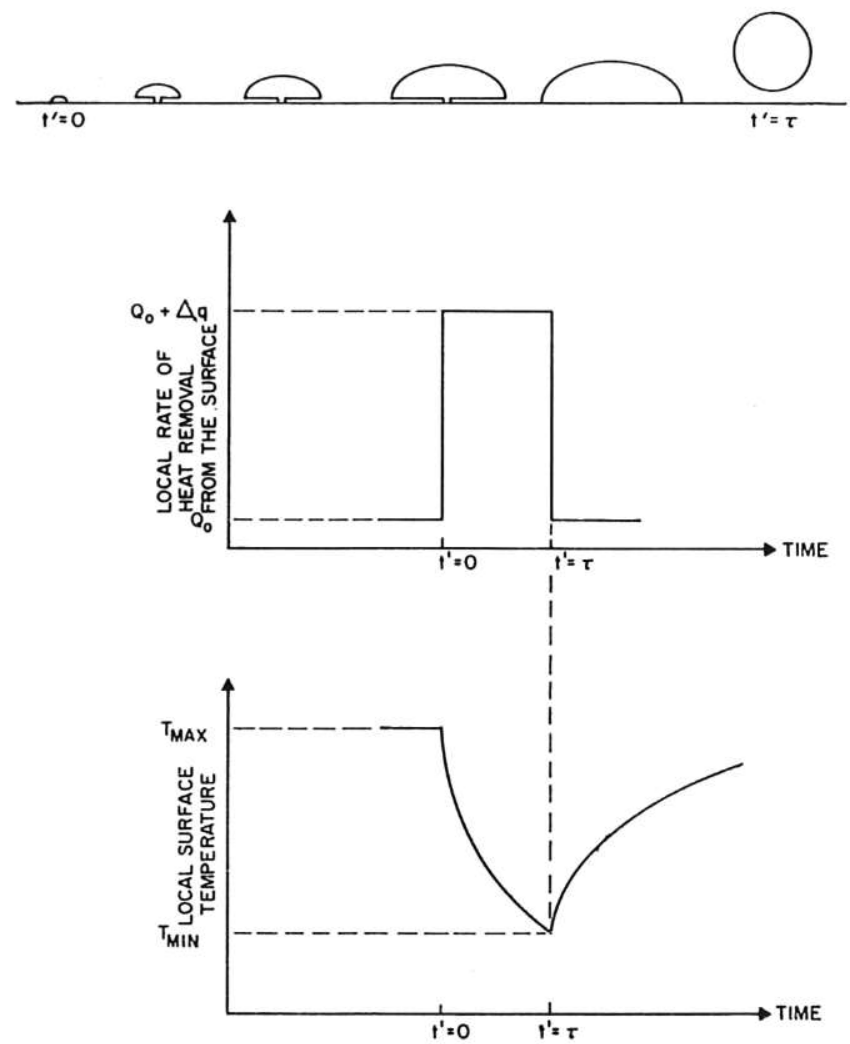

Fig. 6 Schematic representation of the local surface heat flux and local surface temperature during bubble growth from a cavity 


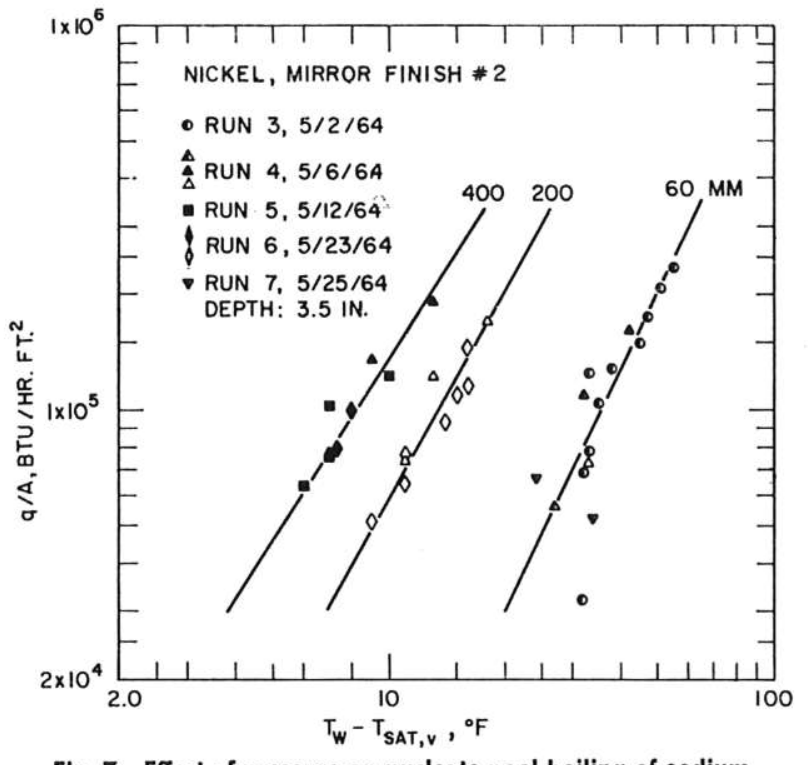

Fig. 7 Effect of pressure on nucleate pool boiling of sodium

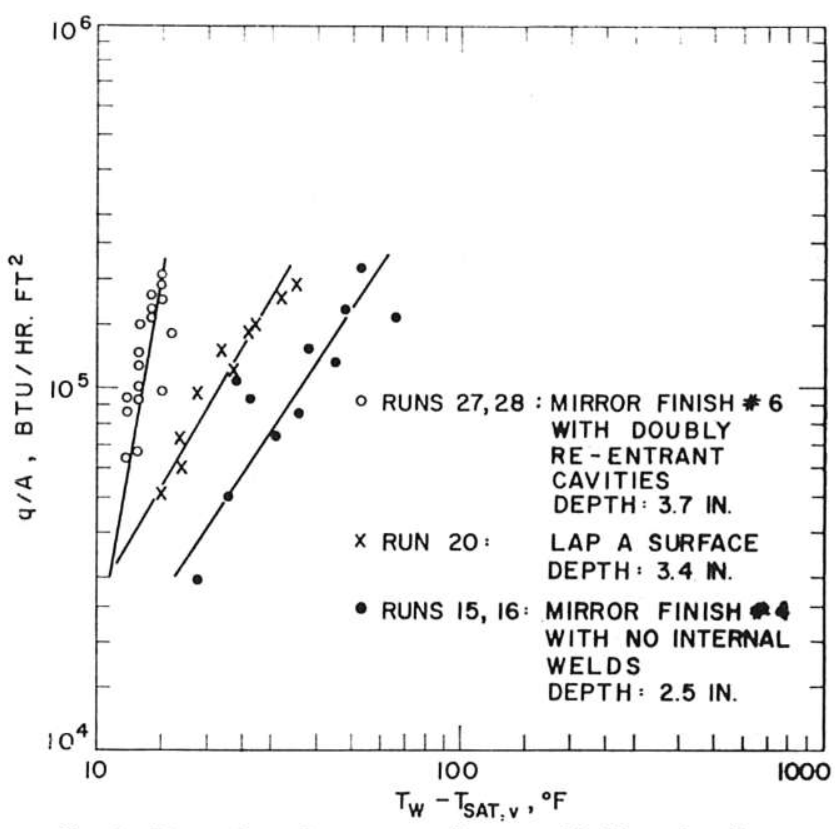

Fig. 8 Effect of roughness on nucleate pool boiling of sodium

bubble, thus reducing the wall surface temperature as shown in Fig. 6. The net result is that the average surface temperature deduced from thermocouple readings in the heater surface is less than the temperature required for initial nucleation. Table 1 lists the magnitudes of $\Delta T_{\mathrm{sat}}$ for stable boiling at a heat flux just above those required for initial nucleation.

\section{Effect of Pressure}

Fig. 7 shows the usual effect of pressure for a nickel "A" mirror surface. As the pressure increases, the curve for $T_{v i}$ in Fig. 5 is displaced downward, requiring lower wall superheat for nucleation and, hence, probably for steady boiling.

\section{Effect of Roughness}

Roughness played a significant role in nucleate boiling of sodium, affecting not only the incipient boiling point but also the wall superheat during stable nucleation and the shape of the boiling curve.

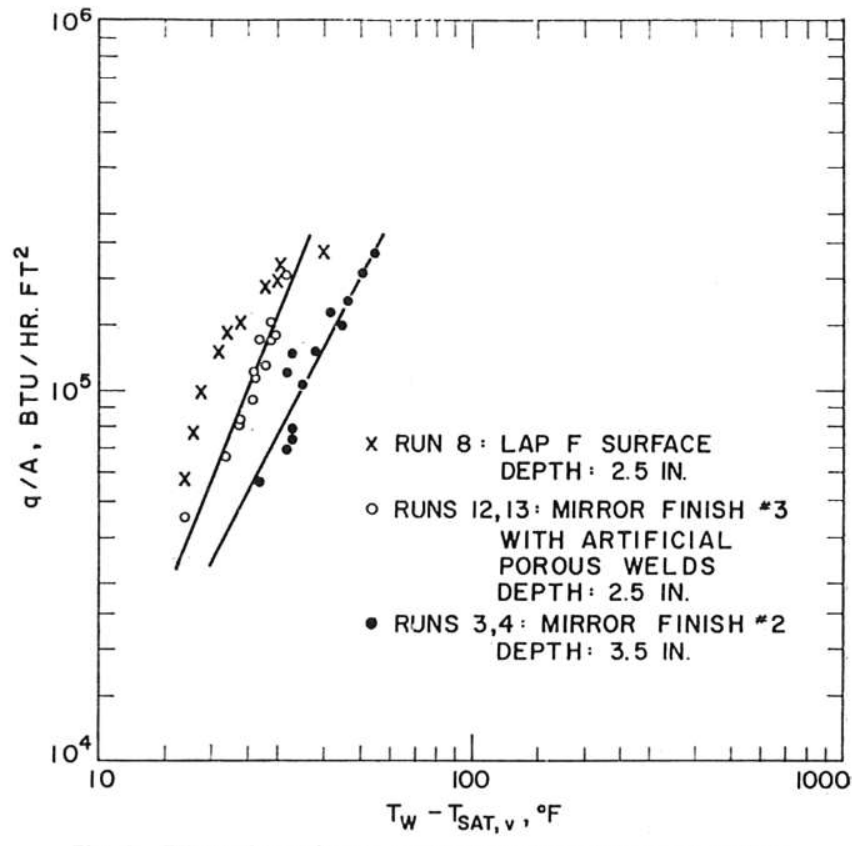

Fig. 9 Effect of roughness on nucleate pool boiling of sodium

Fig. 8 compares the data for a mirror, lap $\mathrm{A}$ and a mirror finish with 12 artificial doubly reentrant-type cavities. It is clear that roughening the surface lowers the wall superheat and generally increases the slope of the data. The large scatter in the mirrorsurface data is a result of the existence of unstable boiling as discussed elsewhere [23].

Fig. 9 shows a similar effect of roughness, comparing the data for mirror 2 , mirror 3 with porous welds, and lap $\mathrm{F}$. The porous welds definitely improve the boiling heat transfer compared with the mirror finish. This fact leads to the conclusion that any welds inside a test section may contain rogue nucleation sites which can alter sodium nucleate-boiling results.

It is interesting to note that both the lap A and lap $\mathrm{F}$ data show a constantly decreasing slope, Figs. 8 and 9 . This shape of the boiling curve may be caused by the particular cavity-size distribution obtained with lapping.

\section{Boiling Hysteresis and Aging Effects}

A considerable amount of hysteresis was observed during nucleate boiling of sodium, Figs. 10 and 11. It appears that noncondensible gases were initially present in many of the runs, lowering the wall superheat. If noncondensible gases are present, then equation (2) becomes

$$
T_{v_{i}}=\frac{T_{\text {sat }}}{\left(1+\frac{p_{g}}{\rho_{v} h_{f o}}\right)-\frac{2 \sigma}{\rho_{v} h_{f o} r}}
$$

The curve for $T_{v_{i}}$ in Fig. 5 shifts downward and would predict lower wall superheats required for initiation of nucleation and, hence, for steady nucleate boiling.

In general, both the incipient boiling point and the stable nucleate boiling wall superheat were lower during the initial phases of a run than after boiling had taken place for some time. Fig. 11 shows that the data of Run 13 (degassed $20 \mathrm{hr}$ ) coincide with the degassed data of Run 12, suggesting that only a few hours degassing time is necessary to remove noncondensibles.

\section{Effect of Porous Coating}

The data for the porous coating are shown in Fig. 12. Here the wall temperature is actually the interface temperature between the solid nickel boiler and the porous plate. Consequently, 


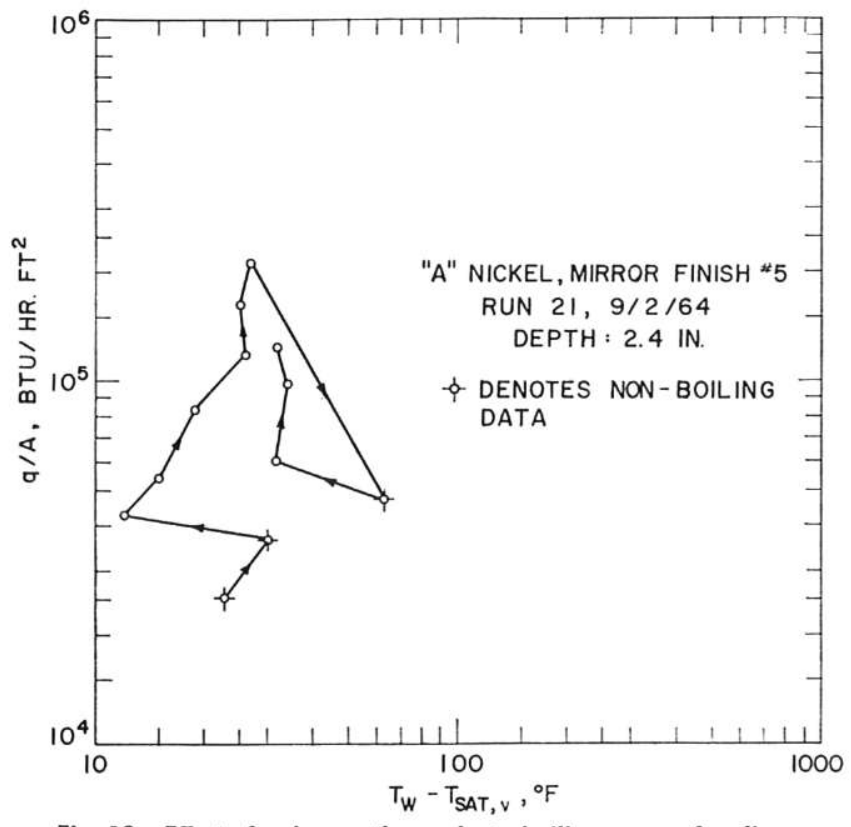

Fig. 10 Effect of aging on the nucleate-boiling curve of sodium

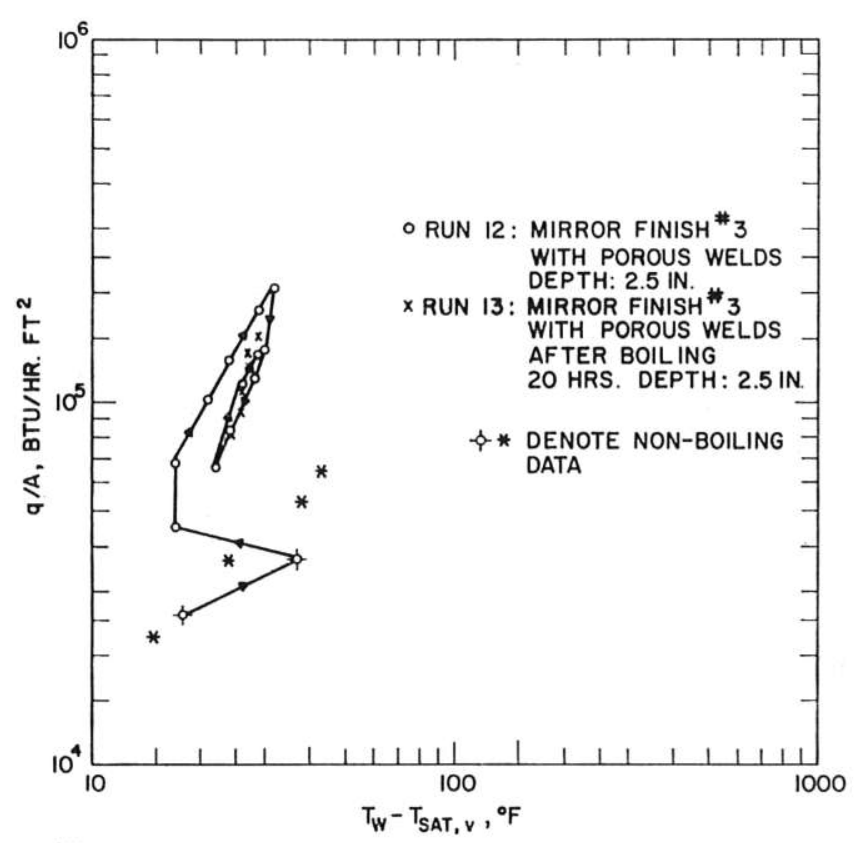

Fig. 11 Effect of aging on the nucleate-boiling curve of sodium

the large thermal resistance across the porous plate is included in the results and this lowers the slope of the data and moves it to higher superheats on the graph. Note that the porous coating nucleates for low heat fluxes at a superheat very near the artificial doubly reentrant cavity data. If the porous coating has a pure conduction resistance, then the temperature drop across it varies linearly with heat flux. When this $\Delta T$ is subtracted from the observed overall $\Delta T$, the nucleate boiling line for the porous coating rotates counterclockwise toward the line for the doubly reentrant cavity data.

\section{Effect of Pool Depth}

Fig. 13 shows the data taken for three different pool depths. The same machined nickel "A" surface was tested in each case, and the inside walls of the boiler pipe were polished to a mirror finish to a height 9 in. above the test surface. The curves are

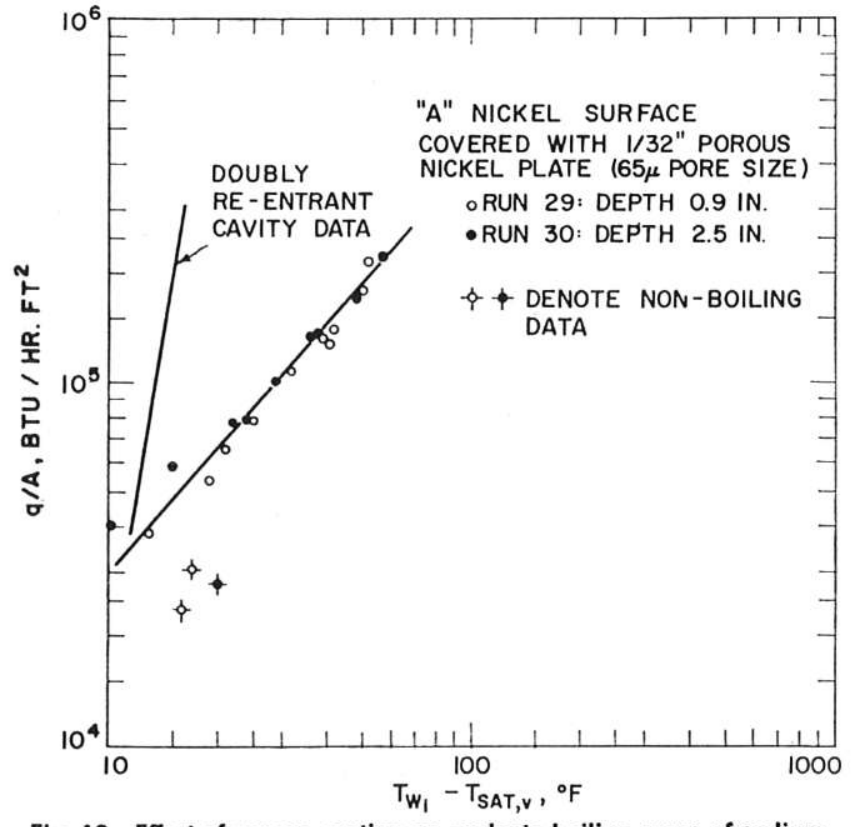

Fig. 12 Effect of porous coating on nucleate-boiling curve of sodium

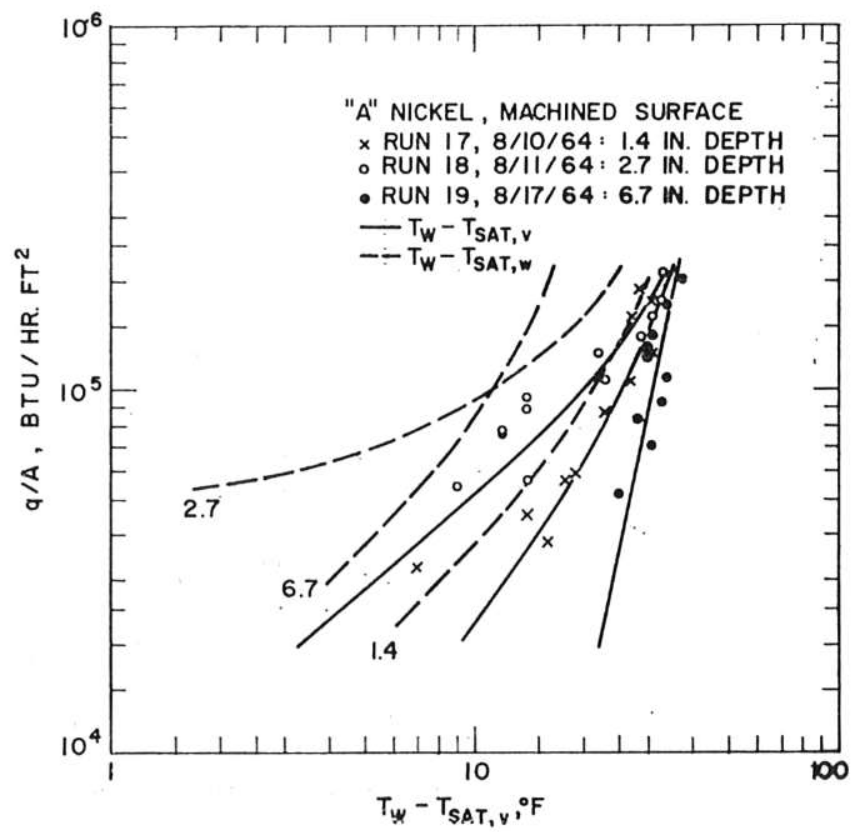

Fig. 13 Effect of pool depth on the nucleate-boiling curve of sodium (abscissa for data points, $T_{\text {Bat }}=T_{\text {sat }}, v$ )

shown plotted with $T_{\text {sat,v }}$ (solid) and $T_{\text {sat,w }}$ (dashed). When plotted against the saturation pressure at the heater surface, the curves (dashed) at the higher heat flux are displaced to the left as depth and hence pressure at the surface is increased, confirming the expected pressure effect. At the lower heat fluxes where boiling is not vigorous, there appears to be a significant influence of natural convection patterns which change with the depth.

\section{Comparison of Results}

The curves in Figs. 8, 9, and 12 for the various surfaces are drawn on a single graph in Fig. 14. As mentioned earlier, $T_{\text {sat, } v}$ corresponds to the pressure in the vapor space. If these data had been plotted against $T_{v}$ minus $T_{\mathrm{sat}, w}$, the curves would shift slightly to the left, but the general arrangement would be unchanged. In fact, the curves for the two mirror finishes would overlap each other. 


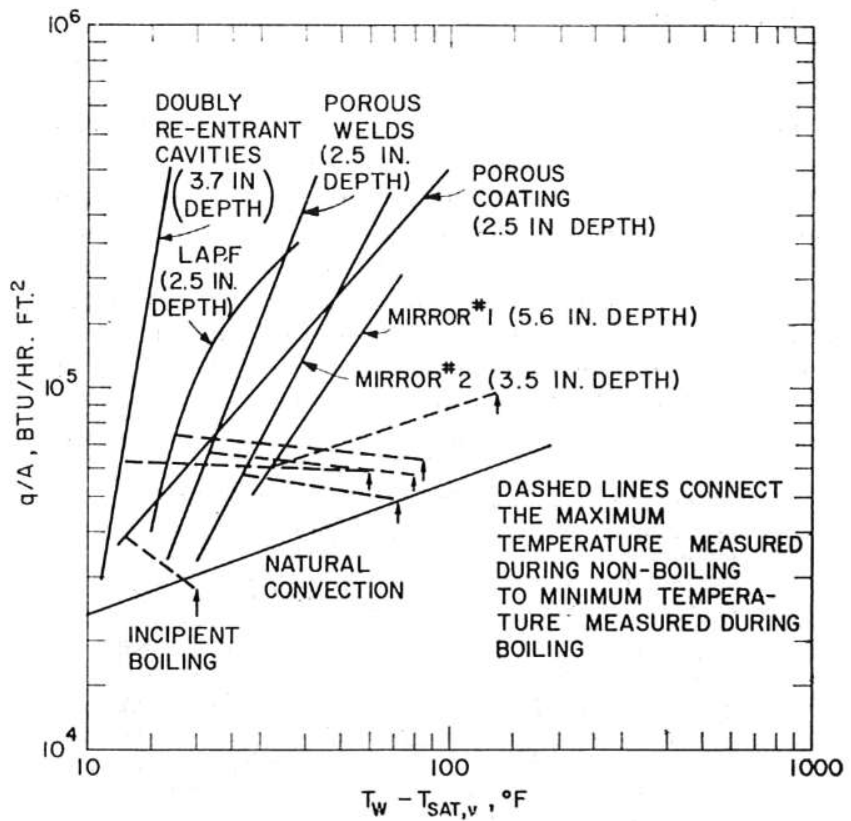

Fig. 14 Comprehensive plot of sodium heat-transfer data at an average pressure of $65 \mathrm{~mm} \mathrm{Hg}$

Throughout this work the following relation between pressure and $T_{\text {sat }}$ was used [24]:

$$
\log _{10} p=4.52172-\frac{5220.42}{T}
$$

\section{Conclusions}

The aforementioned results lead to the following conclusions:

1 Surface roughness and past history can affect significantly the incipient boiling, the nucleate boiling wall superheat, and the slope of the boiling curve of sodium.

2 Any welds inside a test section may contain rogue nucleation sites which can affect sodium nucleate boiling results.

3 The wall superheat required to initiate nucleate boiling of sodium is significantly greater than that required to sustain nucleate boiling.

4 Natural convection in this type of geometry, particularly at low boiling heat fluxes, may have an appreciable influence on the heat-transfer results of sodium.

5 Clearly, nucleate boiling heat-transfer data cannot be correlated without including the effect of surface condition.

\section{Acknowledgment}

This work was supported jointly by the National Science Foundation, National Aeronautics and Space Administration, and the U. S. Atomic Energy Commission. In addition, we are grateful to Prof. Peter Griffith for many helpful suggestions throughout the entire course of this work and to Dr. R. C. Noyes, Dr. R. E. Helms, and Dr. A. F. Sarofim for reviewing in great detail the original design of the apparatus. In retrospect we know that many of their suggestions shortened significantly the time required to obtain the first successful test run.

\section{References}

1 R. E. Lyon, A. S. Foust, and D. L. Katz, "Boiling Heat Transfer With Liquid Metals," Chem. Engr. Prog. Symposium Series No. 17, vol. $51,1955$.

2 N. Madsen and C. F. Bonilla, "Heat Transfer to Boiling Sodium-Potassium Alloy," 3rd National Heat Transfer Conference, Storrs, Conn., 1959.
3 R. D. Brooks, "Alkali Metals Boiling and Condensing Investigations, Vol. I Experimental Program," Final Report, NASA Contract NAS 5-681, 1964.

4 R. C. Noyes, "An Experimental Study of Sodium Pool Boiling Heat Transfer," NAA-SR-6769, 1962.

5 R. C. Noyes, "Boiling Studies for Sodium Reactor Safety, Part 1," NAA-SR-7909, 1963.

6 C. P. Colver, "A Study of Saturated Pool Boiling Potassium Up to Burnout Heat Fluxes," PhD thesis, University of Michigan, 1963.

7 C. Corty and A. S. Foust; "Surface Variables in Nucleate Boiling," AIChE Heat Transfer Conference, St. Louis, Mo., 1953.

8 P. J. Berenson, "Experiments on Pool Boiling Heat Transfer," International Journal of Heat and Mass Transfer, vol. 5, October, 1962.

9 C. F. Bonilla, J. J. Grady, and G. W. Avery, "Pool Boiling Heat Transfer From Scored Surfaces," 6th National Heat Transfer Conference, Boston, Mass., 1963.

10 W. B. Harrison and Z. Levine, "Wetting Effects on Boiling Heat Transfer," ASME-AIChE Heat Transfer Conference, State College, Pa., 1957.

11 T. Dunskus and J. W. Westwater, "The Effect of Trace Additives on the Heat Transfer to Boiling Isopropanol," ASME-AIChE Heat Transfer Conference, Buffalo, N. Y., 1960.

12 E. K. Averin, "The Effect of the Material and of the Mechanical Treatment of the Surface on the Heat Exchange in the Boiling of

Water," Izvestiya Akademii Nauk SSSR, Otdelenie Tekhnicheskikh Nauk, vol. 3, 1954 (AERE-Lib/Trans-562) pp. 116-122.

13 B. J. Stock, "Observations on Transition Boiling Heat Transfer Phenomena," ANL-6175, 1960.

14 R. K. Young and R. L. Hummel, "Higher Coefficients for Heat Transfer With Nucleate Boiling," 7th National Heat Transfer Conference, Cleveland, Ohio, 1964

15 M. H. Wahl, MSA Research Corp., Private correspondence, 1962 .

16 C. C. Addison, E. Iberson, and J. A. Manning, "The Role of Oxide Films in the Wetting of Iron, Cobalt and Nickel by Liquid Sodium, and by Solutions of Barium and Calcium in Liquid Sodium," Journal Chem. Soc., July, 1962, pp. 2699-2705.

17 A. E. Bergles and W. M. Rohsenow, "Forced Convection Surface Boiling Heat Transfer and Burnout in Tubes of Small Diameter," MIT Report No. 8767-21, 1962.

18 Y. Y. Hsu, "On the Size Range of Active Nucleation Cavities on a Heating Surface," Journal of Heat Transfer, Trans. ASME, Series C, vol. 84, 1962 pp. 207-216.

19 R. E. Balzhiser, "Investigation of Boiling Liquid Metal Heat Transfer," University of Michigan, Report RTD-TDR-63-4130, 1963.

20 H. W. Hoffman and A. I. Krakoviak, "Convective Boiling With Liquid Potassium," Heat Transfer and Fluid Mechanics Institute, Stanford, California, 1964 .

21 F. D. Moore and R. Mesler, "The Measurement of Rapid Temperature Fluctuations During Nucleate Boiling of Water," AIChE Journal, 1961.

22 C. Bonnet, E. Macke, and R. Morin, "Visualisation de L'ebullition Nuclee de L'eau a Pression Atmospherique et Mesure Simultanee des Variations de Temperature de Surface," EUR 1622.f, Ispra, Italy, 1964 .

23 P. J. Marto and W. M. Rohsenow, "The Effect of Surface Conditions on Nucleate Pool Boiling Heat Transfer to Sodium," MIT Report No. 5219-33, January, 1965.

24 C. F. Bonilla, D. L. Sawhney, and M. M. Makansi, "Vapor Pressure of Alkali Metals, III Rubidium, Cesium, and SodiumPotassium Alloy Up to 100 Pounds per Square Inch," Proceedings of 1962 High-Temperature Liquid-Metal Heat Transfer Technology Meeting, BNL 756, 1962.

\section{APPENDIX \\ Hydrostatic Head Correction to $\mathrm{T}_{\text {sat }}$}

Because of a hydrostatic head of the depth of sodium above the heating surface, the saturation temperature at the heating surface $T_{\text {sat, } w}$ is greater than that in the vapor space $T_{\text {sat,v. }}$ The magnitudes for various depths and absolute pressures are shown in Table 2.

\begin{tabular}{cccc}
\multicolumn{4}{c}{ Table 2 } \\
\multicolumn{4}{c}{$T_{\text {sat, wo }}-T_{\text {sat, }, ~}$ deg F } \\
at pressures of \\
Depth, in. & $60 \mathrm{~mm} \mathrm{Hg}$ & $200 \mathrm{~mm} \mathrm{Hg}$ & $400 \mathrm{~mm} \mathrm{Hg}$ \\
1.4 & 4.5 & 1.6 & 0.7 \\
2.5 & 7.7 & 2.8 & 1.5 \\
6.5 & 18.4 & 7.2 & 4.0
\end{tabular}

